\title{
Sonho de arquivo
}

RESUMO: O presente artigo busca analisar as noções de arquivo e de prática de arquivo a partir das reflexões de Walter Benjamin. Buscaremos compreender a novidade do método benjaminiano mostrando sua forma de exposição da obra do poeta Charles Baudelaire. A partir da correspondência entre Benjamin e Adorno, apresentaremos o dispositivo desenvolvido por Benjamin e que se trata não de interpretar a obra de Baudelaire, mas antes de expô-la. Expor essa obra significa, para Benjamin, um engajamento histórico-político do teórico-analista-arquivista e a tensão de suas contradições enquanto sujeito singular histórico. Essas contradições não são resolvidas, mas identificadas e imobilizadas como tal.

PALAVRAS-CHAVE: Benjamin, arquivo, arte, história

ABSTRACT: The present paper aims to analyze the notion of archive and archive practice as developed in Walter Benjamin's thought. We will try to understand the innovation of the benjaminian method. For that, we will show how the Benjaminian exposition method of Charles Baudelaire's work operates. Having as starting point the correspondence between Benjamin and Adorno, we will present the device developed by Benjamin and how it is question not of interpreting Baudelaire's works, but rather of exposing them. To expose his works means, to Benjamin, a historical and political engagement of the theorist-analyst-archivist and the tension of his contradiction as singular historical subject. These contradictions are to be identified and immobilized as such rather than solved.

KEYWORDS: Benjamin, archive, art, history *Professora de Estética da Université Paris 8, é autora de L'Enseignement de la Torture, (Paris: Le Seuil, Bibliothèque du XXle siècle, 2013),
Walter Benjamin sans Destin (Paris: Éditions La Différence, 1992, reeditado com novo prefácio em 2007 em Bruxelas: La Lettre volée,
2007) e Marcel Duchamp, le Manieur de Gravité, Paris (Éditions CNDP, 1998), entre outras obras. E-mail: catherineperret333@orange.fr 
Até hoje, o pensamento de Walter Benjamin tem sido tomado sobretudo do ponto de vista da estética e da filosofia da história. Estas problemáticas permanecem como os eixos principais do trabalho crítico e analítico feito sobre a obra de Benjamin. Entretanto, um terceiro eixo parece atualmente emergir em função da recepção de seu trabalho por artistas, especialmente no que concerne artistas que trabalham na perspectiva do "arquivo." A intenção das observações que seguem é entender de que maneira a teoria e a prática benjaminianas do arquivo podem esclarecer a potencialidade dessas formas. ${ }^{1}$

No catálogo de apresentação da exposição Archive Fever, exibida no MOMA, em 2005, o curador Okwui Enwezor esboça uma primeira genealogia do fenômeno do "arquivo" tal como ele tem determinado inúmeras práticas artísticas contemporâneas.

\footnotetext{
A Boîte-en-Valise, na qual Duchamp instalou sua obra já existente em forma de reproduções, a heterogeneidade de dispositivos de curadoria do Département des Aigles ou o perpétuo comentário de Richter acerca da fotografia como objeto mnemônico [...] formam uma lógica de domiciliação e de consignação reagrupando os signos que designam a obra do artista assim como a condição material das proposições feitas por cada uma dessas obras, a narrativa que ela deve veicular, 0 arquivo a priori da prática do artista. (Grifo meu)
}

Essa última formulação é interessante. Independentemente das referências explícitas e implícitas $^{2}$ que articulam seu horizonte artístico e intelectual, a ideia de um "arquivo a priori da prática" indica o ponto de báscula histórica onde se encontra Enwezor, que fora o diretor da Documenta em 1998, e que, sete anos mais tarde, busca fazer um primeiro balanço das práticas de arquivo na arte na virada do século XXI.

Lá onde a questão é efetivamente de prática, é questão também de tempo, do après coup e do a posteriori. E, supondo que toda prática autoriza o arquivamento da produção do artista, este arquivamento não é contemporâneo à produção ela mesma - de modo que ele se desenvolve em função de modos de reprodução variáveis ao longo da vida do artista. Do urinol industrial de 1917 ao urinol feito à mão em 1965, as retomadas sucessivas por Duchamp de seus ready-mades oferecem uma ilustração magistral. O arquivamento não se contenta em arquivar. Ele historiciza a obra em curso. Por isso, não há Arquivo no singular.

No contexto dessa pós-modernidade ideológica onde a questão da história poderia parecer neutralizada (apesar do 11 de setembro e da guerra do Iraque), a noção oximórica de "arquivo 
a priori da prática" é sintoma da impossibilidade de pensar práticas artísticas fazendo economia de uma filosofia da história - sobretudo porque essas práticas se pensam em termos de arquivo(s).

É aqui que, muito além das tendências do mercado do pensamento, o nome de Walter Benjamin se impõe com uma insistência renovadora. Para Benjamin, com efeito, prática histórica e prática artística são indissociáveis. Elas o são, em primeiro lugar, em sua trajetória como escritor. Face à expansão do nazismo, quando ele procura se definir não mais como crítico, mas como "historiador", a questão da arquitetura do texto passa ao primeiro plano de sua reflexão sobre a escrita. Sua prática de arquivos nasce no ponto de cruzamento dessa dupla prática de historiador e escritor. Concomitantemente à coleta de arquivos em vista desse monumento ao século XIX que viria a ser o Passagenwerk, Benjamin elabora um método de exposição desses arquivos cuja aposta é a proposição de outra epistemologia da história.

Essa invenção, Benjamin a menciona uma primeira vez em uma carta de 1935 a seu amigo Werner Kraft:

No que me diz respeito, me esforço em direcionar meu telescópio através da neblina ensanguentada para uma miragem do século XIX; me esforço em desenhá-la segundo os traços por ele revelados em um mundo porvir, liberado da magia. Naturalmente eu preciso começar construindo eu mesmo esse telescópio, e nesse esforço fui o primeiro a encontrar algumas proposições fundamentais da estética materialista. (BENJAMIN, 1978, p. 698-699) ${ }^{3}$

Ele volta à mesma questão na correspondência com Adorno, após a recusa do Institut für Sozialforschung de publicar o artigo sobre Baudelaire considerado por ele um primeiro protótipo do Passagenwerk. Mas, nessa troca célebre e frequentemente comentada, Adorno é menos sensível à construção desse telescópio textual revolucionário do que aos efeitos de interferência visual que ela opera na exposição dialética do material:

Panorama e traço, flâneur e passagem, modernidade e sempre o mesmo, sem interpretação teórica - é esse o material que pode esperar pacientemente que seja interpretado sem que sua própria aura o devore? [...] A objeção não se aplica unicamente ao caráter questionável de omitir uma coisa que, em razão da recusa ascética de interpretação, me parece entrar justamente na zona a qual a ascese se opõe: lá onde história e magia oscilam. (ADORNO in BENJAMIN, 1978, p. 783-784). 
Em outros termos: sem interpretação à vista, as intenções dos textos permanecem indecifráveis.

Adorno interpreta essa ascese como um efeito de autocensura de Benjamin, convencido de que o Instituto exigiria dele um artigo politicamente correto, "marxistamente" correto, onde se interditaria todo abandono à pura especulação. Que teria desejado Adorno? Que Benjamin se permitisse abandonar à sua natureza especulativa e à espécie de dialética infusa que caracteriza seu temperamento teórico, que ele não tomasse tantas precauções com o que se esperaria dele - ou seja, um texto materialista dialético -; que ele deixasse essa força especulativa neutralizar a falsa objetividade produzida pela exposição de um material filológico "bruto de descofragem". "Apenas a teoria seria capaz de romper com a fascinação: sua própria, implacável, boa teoria especulativa". (ADORNO in BENJAMIN, 1978, p. 786)

Benjamin permanece firme em sua posição diante dessa crítica. E o que ele opõe a Adorno pode se resumir nesses termos: eu não me oponho à interpretação, pois a interpretação não é o objetivo desse texto. A interpretação de Baudelaire não é ela mesma senão uma peça do telescópio em construção. A questão não é interpretar Baudelaire, mas antes expô-lo. A especulação é não o objetivo, mas uma alavanca que serve à construção.

Eu acredito que a especulação só alça seu voo necessariamente audacioso com perspectiva de êxito se, em vez de vestir as asas enceradas do esoterismo, ela busca toda sua força na construção de sua fonte de energia. A construção requer que a segunda parte do livro [o ensaio sobre Baudelaire] seja essencialmente constituída por um material filológico. Trata-se menos de uma "disciplina ascética" que de uma medida metodológica. (BENJAMIN, 1978, p. 793)

O artigo proposto ao Institut für Sozialforschung não é senão um ato, dentre outros, de um mesmo drama. É preciso lê-lo como tal. Como elemento deste protótipo em devir.

Adorno, por sua vez, e nas delicadas circunstâncias históricas nas quais se encontra o Instituto, aprecia menos a experimentação como se essa se afastasse da "verdade".

Não há em nome de Deus senão uma única verdade, e se pela sua potência do pensamento você se apoderar dessa verdade através de categorias - que segundo sua ideia do materialismo Ihe parecem apócrifas - então você poderá melhor se apropriar dessa verdade do que se você se servir de uma armadura conceitual que a sua mão recusa constantemente tocar. (ADORNO in BENJAMIN, 1978, p. 787-788) 
Observa-se em Adorno a ideia de que a especulação, caso Ihe seja dada livre curso, poderia interromper o circuito da reflexão, e, seguindo ainda essa ideia, a suposição de que o caráter especulativo é expressão do movimento do Espírito ele mesmo. Em outros termos: seria mais proveitoso se Benjamin houvesse posto sua natureza teórica a serviço da máquina dialética do Espírito.

Mas o tema que Benjamin procura engajar na construção do telescópio não é o Geist. É o sonhador. Ele o revela, en passant, a Adorno na mesma carta.

Se eu me recusei, em nome dos meus próprios interesses produtivos, a adotar um desenvolvimento de pensamento esotérico [que ele entende como especulativo] e desse modo assumi os interesses do materialismo dialético e do Instituto, não o foi unicamente por solidariedade ao Instituto, nem por pura fidelidade ao materialismo dialético, mas por solidariedade à experiência que todos nós, nos últimos quinze anos, temos vivido. Trata-se aqui ainda dos meus mais próprios interesses produtivos; eu não quero negar que eles possam tentar ocasionalmente violentar os meus interesses primitivos. Há aí um antagonismo que mesmo em sonho eu não poderia desejar me ver liberado. A sua superação fixa o problema do trabalho - o problema e sua construção fazem um. (BENJAMIN, 1978, p. 793)

Passagem extraordinária na qual o propósito do Benjamin teórico se desfaz ante o desejo do Benjamin sonhador. Para se compreender o sentido desse gesto, convém esclarecer o conflito mencionado por Benjamin entre seus interesses primitivos e seus interesses produtivos. Os primeiros designam seus interesses de classe enquanto herdeiro da grande burguesia judaica assimilada; os outros, seus interesses como autor, "de autor como produtor" 4 , no contexto da Alemanha nazista.

Com o sonhador, não é o "eu" que Benjamin introduz na teoria, mas o sujeito indissociavelmente singular e plural, o sujeito solidário, ou, dito de outro modo, o sujeito dividido entre o que o faz "um" e o que o faz "vários", em função da responsabilidade sentida diante das experiências "nossas". Acerca desse problema, Benjamin afirma que mesmo em sonho ele não desejaria ser liberado de tal conflito que o divide.

A ideia pode parecer paradoxal ao leitor habituado à tese de que o sonho exprimiria a realização de um desejo. Poderia o sonho exprimir o desejo de permanecer preso em um conflito insolúvel, em um conflito que é possível construir, mas não ultrapassar? 
A fórmula se explica no entanto a partir do que nos foi transmitido tanto pelas narrativas de sonho contadas por Charlotte Beradt, quanto pelas considerações de Hannah Arendt acerca da atmosfera alucinatória criada pela violência nazista para o cidadão alemão "normal". O pesadelo próprio a esses anos de expansão do nazismo não é somente a violência de atos ou discursos: é o clima de loucura ambiente que parecendo "desrealizar" a situação, paralisa a ação. O que o sonho sonha então, o que o sonhador deseja, é liberar-se da fantasmagoria criada pela violência, é recuperar seu lugar no real e no seio dos antagonismos que o dividindo, Ihe devolvem uma realidade dotada de sentido.

Introduzindo esse sujeito solidário que sonha "em não ser liberado de seus antagonismos", para assim se tornar apto a "desenhar a miragem" da modernidade através da neblina ensanguentada do presente, ou dito de outro modo, para se tornar capaz de fazer a arqueologia do nazismo enquanto um fenômeno "moderno," Walter Benjamin introduz uma hipótese metodológica nova. O saber histórico não cabe ao sábio. Ele cabe ao sujeito da história concreta, e por história concreta Benjamin entende as experiências compartilhadas. Ora, o que nós dividimos hic et nunc, o que "nos" faz trabalhar, são duas coisas: "isso que nós devemos nos lembrar", o memorável, e este sonho: o sonho de despertar do pesadelo decretado realidade.

A aparência de facticidade fechada sobre ela mesma, que se liga ao estudo filológico e que fascina o pesquisador, desaparece na medida em que o objeto é construído em uma perspectiva histórica. As linhas de fuga dessa construção se encontram na nossa própria experiência histórica. (BENJAMIN, 1978, p. 794)

Benjamin responde então a Adorno - que, ao que tudo indica, não capta a importância dessa menção ao sonho - penetrando no coração de seu trabalho histórico não como pesquisador, mas antes sonhando que os arquivos devam reconduzir, através dos fatos, ao memorável, mesmo que ele seja doloroso.

Benjamin, em sua carta a Adorno, persegue de modo bastante consequente a ideia do sonho: para sonhar é preciso fazer-se noite. Trata-se aí do trabalho de acúmulo de arquivos ${ }^{5}$. É então, no papel do pensamento do sonhador, que a interpretação opera tal como um raio luminoso projetado sobre o fundo do arquivo recopiado, acumulado, obscuro. "Ela [a teoria] irrompe como um único raio luminoso em uma câmara artificialmente obscurecida. Mas esse raio, decomposto no prisma, basta, pela textura da luz, para fornecer um conceito cujo foco se encontra na terceira parte do livro". (BENJAMIN, 1978, p. 792) 
É o enunciado mesmo do método. Ele se inspira menos no telescópio evocado a Werner Kraft que na câmera escura. Trata-se - através do agenciamento dos materiais de arquivo - de construir o equivalente textual de uma camara oscura, na qual se fará passar um raio luminoso de modo a fazer aparecer no fundo da caixa o que Benjamin invoca no título de um outro ensaio sobre Baudelaire: Einige Motive. Alguns motivos ${ }^{6}$. O método de Benjamin comporta assim três momentos: a opacificação do material, a projeção de um único raio luminoso teórico, a impressão de motivos que surgem no fundo da caixa da câmera escura assim realizada. Dediquemos um breve tempo a detalhar essas operações.

A primeira operação consiste em obscurecer o espaço no qual nós pensávamos poder ler Baudelaire a olho nu e à luz do dia. Para tal, basta apresentar o texto de Baudelaire através da impressão que ele deixou no discurso dos leitores: tal como ele foi arquivado por meio de sua reinscrição sucessiva em diversos textos, de especialistas ou não, contemporâneos ou não. Através dessa operação, os traços que o texto de Baudelaire depositou na cultura são postos em um mesmo nível. Os traços se sedimentam em uma noite textual que desmente a falsa esperança de alcançar a coisa "em si". Diante de nós, não há mais Baudelaire, mas um "material-Baudelaire." Basta abrir o livro das Passagens para vermos essa caixa escura de arquivo acumulado. Não insistirei sobre esse ponto.

Em seguida - eis a segunda operação - trata-se de esclarecer em um ponto, e em um único ponto, esse material abandonado à sua obscuridade. $O$ trabalho feito pela fonte luminosa é justamente a aplicação da teoria marxista da alma da mercadoria na alegoria baudelairiana.

O ponto de partida dessa interpretação, o que ela teoriza propriamente, é a célebre fórmula: "Créer um poncif, c'est le génie"7. Não seria ela uma tradução notável da teoria marxista da forma do valor em termos de forma literária? "Seu modelo, a alegoria, de fato correspondia de maneira perfeita ao fetichismo da mercadoria". (BENJAMIN, 2007, p. 414, J 79a, 4)

Nunca se poderá saber ao certo por que tal mercadoria tem tal preço, nem no curso de sua fabricação, nem mais tarde quando ela se encontra no mercado. Ocorre exatamente o mesmo com o objeto em sua existência alegórica. Nenhuma fada determinou em seu nascimento qual o significado que lhe atribuirá a meditação absorta do alegorista. Porém, uma vez adquirido tal significado, este pode ser substituído por outro a qualquer momento. As modas dos significados mudam quase tão rapidamente quanto o preço das mercadorias." (BENJAMIN, 2007, p. 414 , J 80, 2 / J 80a, 1) 
Em Marx, a forma do valor é oriunda de um processo de transubstanciação do uso no valor de troca. Ela se apresenta como uma forma de duas faces na qual a quantidade abstratizada de trabalho realizada no produto (mais-valia) se torna qualidade alucinada na mercadoria. Uma abstração sensível. Ou, na fórmula de Marx, "um corpo transparente de valor".

O que faz da alegoria baudelairiana a fórmula poética da forma de valor no capitalismo industrial do século XIX é sua dupla figuralidade: por um lado a abstração do significante sob a forma da língua reificada da utilidade, e por outro o pathos do significado: a melancolia do sujeito identificado à mercadoria. A alegoria é a forma da equivalência, na poética baudelairiana, entre o estereótipo de fragmentos inertes da linguagem ordinária (clausura ${ }^{8}$, saquinho ${ }^{9}$, planos $^{10}$, bainha ${ }^{11}$ ), e o lirismo do significado ao qual esse significante interpela: o eterno retorno do mesmo, a forma do tempo petrificado na moda.

O que aparece então ao termo dessa projeção, no fundo da câmera escura do arquivo-baudelaire, são "motivos". Curiosamente Adorno, músico, desliza sobre a significação musical do termo. Ele interpreta o termo como se se tratasse de termos literários (o flâneur, a multidão...) e acusa Benjamin de tê-los reunidos sem no entanto chegar a articulá-los: "Os motivos foram reunidos, mas não trabalhados". (BENJAMIN, 1978, p. 783) Entretanto, o que surge na noite textual do arquivo não podem ser produtos sintéticos do espírito do tempo como são os temas literários. São formações elas mesmas textuais: efeitos de recorrência cujo essencial é menos a essência do que volta constantemente - o significado melancólico sinalizado pelas letras maiúsculas baudelairianas -, mas antes a dinâmica da retomada. Esta imprime na superfície do texto uma série de minúsculos desmoronamentos: prosaísmos, impotências semânticas, decaimentos do timbre e da língua que fazem "furos" no desenvolvimento neoclássico do soneto baudelairiano. Proust, lembra Benjamin, caracterizava esses processos como "claudicações" do verso. "Cibele, que os adora, o verde faz crescer"12. Após a evocação mitológica de Cibele, a Grande Mãe, o leitor esperaria alguma exuberância semântica. E eis que a pressão baixa: não é a natureza que cresce, mas a "verdura" - que evoca antes uma horta da periferia que a natureza.

A novidade da abordagem benjaminiana não é a de ressaltar o fenômeno do desmoronamento recorrente da poética baudelairiana: Marcel Proust, Paul Valéry, Jacques Rivière, Jules Laforgue já haviam apreendido o fenômeno e identificado sua forma. A novidade é de ordem estritamente metodológica. Ela consiste em não interpretar esse efeito em seu nome próprio, 
diretamente. Benjamin faz surgir sua interpretação indiretamente, "em imagem", mediatizada pelo comentário feito por esses autores. A novidade consiste, uma vez posto o axioma da interpretação, em projetá-lo, tal como um feixe de luz, no material-Baudelaire. Ele se contenta, em seguida, em recolher a impressão da poética baudelairiana nos registros feitos por Proust, Valéry, Rivière ou Laforgue - como um arquivo gravado e cantarolado por outros que não Baudelaire ou ele mesmo. O que chega então ao leitor é a imposição de um desejo, cujo eco repercute de texto em texto, na forma de motivos que, como vozes, assombram a modernidade. $\mathrm{O}$ arquivo benjaminiano não incita nem o espírito especulativo, nem a voz original de seu objeto, mas o desejo de Baudelaire incorporado pelo sonho do sujeito histórico que o reproduz, até o ponto em que o arquivamento, se apropriando do processo de sua reprodução, o projeta em imagem, em "miragem".

Diversos artistas arquivistas estão ainda hoje em busca de um tal telescópio, suscetível de atravessar a neblina ensanguentada do presente, de fazer emergir a ambivalência desse passado, os efeitos incessantes dessa ambivalência e de nos permitir ouvir a ventriloquia do sujeito histórico. Benjamin, em sua correspondência com Adorno, nos lega um ensinamento: essa ventriloquia somente é acessível com a condição de que o historiador se engaje, em nome do desejo, em permanecer fiel aos conflitos que o atravessam. Em nome da solidariedade que o une aos seus contemporâneos. Como sujeito político, cujo arquivo não é somente a memória, mas o corpo.

Tradução: Marlon Miguel

\section{Notas}

1 Essas notas foram retomadas de uma conferência proferida em 30 de outubro de 2013, no Rio de Janeiro.

2 Jacques Derrida para a "domiciliação," Michel Foucault para a "consignação"

3 Todas citações do texto foram traduzidas do original - com exceção do Livro das Passagens, que usamos a edição brasileira. No caso da correspondência de Benjamin, a autora usou sempre a edição alemã das obras completas e em alguns casos colocou ao lado a tradução francesa. Optamos então por traduzir do alemão, consultando em alguns casos a versão francesa. [Nota do tradutor] 4 Título de um texto desse mesmo período.

5 É preciso lembrar a esse respeito que Benjamin copia à mão milhares de citações - uma atividade hipnótica.

6 Trata-se em português do texto "Sobre alguns temas em Baudelaire" (Uber Einige Motive bei Baudelaire). [Nota do tradutor] 
7 A expressão aparece em Fusées (XX), publicado como parte dos Diários Íntimos de Baudelaire. A tradução de poncif é difícil, mas remete a estereótipo, a lugar comum ou a banalidade. [Nota do tradutor]

8 Trata-se da palavra cloison (ver poema XXXVI, A varanda, de Flores do Mal). A edição brasileira, com tradução de Ivan Junqueira, traduziu a palavra por "clausura".Trata-se entretanto de uma palavra mais ordinária no francês (algo como uma "pequena divisória", uma parede ou um biombo) que o poeta usa metaforicamente. Esse é um problema recorrente da tradução brasileira, que procurando dar conta dos significados invocados por Baudelaire, acabou por reduzir ou simplificar a forma literária, os significantes. [Nota do tradutor] 9 Sachet, no original. Ver p.e. o poema O perfume de Flores do Mal. [Nota do tradutor]

10 Bilan, no original. Ver p.e, o poema Spleen de Flores do Mal. [Nota do tradutor]

11 Ourlet, no original e traduzido por Ivan Junqueira por "barra do vestido" (Ver A uma passante de Flores do Mal). [Nota do tradutor]

12 "Cybèle qui les aime augmente ses verdures", no original. Trata-se de um verso de Ciganos em viagem (Bohémiens em voyage), de Flores do Mal. "Verdure" é o verde, a folhagem, mas também a verdura ou o legume, o que explica a interpretação que segue da autora. [Nota do tradutor]

\section{Referências}

BENJAMIN, Walter. Briefe I. Frankfurt: Suhrkamp, 1978.

BENJAMIN, Walter. Gesammelte Schriften Bd.4. Frankfurt: Suhrkamp, 1991b.

BENJAMIN, Walter. Passagens. Belo Horizonte: Editora UFMG, 2007. 